\title{
How Much Gender is Too Much Gender?
}

\author{
ROBIN DEMBROFF \\ YALE UNIVERSITY \\ DANIEL WODAK \\ UNIVERSITY OF PENNSYLVANIA*
}

\section{The Linguistic Spectrum}

Languages form a spectrum from having fewer to more gender-specific terms. On one end of the spectrum we have languages like Hebrew. As Ilana Masad explained in an article on The Toast, in Hebrew "one cannot speak in the first- or second-person without indicating gender. The word ' $\mathrm{I}$ ' is ungendered, but any verb connected to it in present or future tenses is gendered. Thus the phrase, "I want a cookie" becomes, in literal translation, "I female-want a female-cookie"."1 On the other end of the spectrum, we have languages like Finnish, which does not have grammatical gender or any gender-specific pronouns.

Somewhere between Finnish and Hebrew, we find English. ${ }^{2}$ Certain parts of speech in English are gender-specific-for instance, singular third-person pronouns (he and she). This makes English more gendered than languages like Finnish. But first- and second-person pronouns ( $I$ and you), and the verbs connected to them, are gender-neutral in English, which makes English less gendered than languages like Hebrew.

\footnotetext{
* Authors are ordered alphabetically, and are equally responsible for the content. They would like to thank Emma Marja Atherton, Sukaina Hirji, Matthew McKeever, Andrea Pitts, Michael Rae, Kevin Timpe, the editors, and of course Nala and Eli.

${ }^{1}$ Ilana Masad, 'On Hebrew and Living in Gendered Language', The Toast, March 172015 $<$ http://the-toast.net/2015/03/17/hebrew-living-gendered-language/>

${ }^{2}$ We use this comparison following Guiora (1983: 231): “We can summarize the differences in the extent to which these languages obligate speakers and addressees to note their own and others' gender by saying that the sex-determined grammatical "gender loading" of languages varies from almost zero in languages like Finnish and Hungarian, through very low in English, to very high in Hebrew." Note that languages like Finnish, though often classified as 'genderless', still have some gendered terms.
} 
The central question we explore is: Where on this spectrum should English be? As English speakers, should we collectively push our language to be more or less gendered?

Of course, English could be exactly where it ought to be on this spectrum. But in a way, that would be surprising. Languages shift along this spectrum as a result of changes in how we write and speak. ${ }^{3}$ Why think English now happens to get things exactly right?

There are related questions for non-English languages, of course. And people take them seriously. Masad goes on to describe subtle forms of activism that Israeli feminists and LGBTQIA communities have engaged in-often deliberately flouting the rules set by the Academy of Hebrew Language-such as mixing up gender-specific verbs ("I am male-going to the gallery and female-buying art"). We focus on the English case because that's what we know. However, at least prima facie, arguments in this context should generalize to other languages: if you think English is currently as gendered as it ought to be, there's some pressure to think that Finnish should be more gendered and Hebrew should be less gendered, though that pressure is of course defeasible. ${ }^{4}$

Our view is that English should be no more gender-specific than it is currently racespecific with respect to four parts of speech: pronouns, honorifics, suffixes, and generics. (We'll discuss other forms of gendered and racially coded language in Section 5). Exactly what this means will become clear in a moment, but for now we can say that it would make English far less gendered even than languages like Finnish. We conclude by considering reasons for and against de-gendering English further still.

\section{The Analogy to Race-Based Language}

It can be hard to evaluate gendered practices in which we're enmeshed; sometimes we need to get some distance. One way to do this is to consider hypothetical languages that treat some other social category the exact same way English currently treats gender. We will pursue this using an analogy between gender- and race-specific language from Douglas Hofstadter's 'A Person Paper

\footnotetext{
${ }^{3}$ An interesting case is the introduction of gender-specific third-person pronouns in Chinese in the $20^{\text {th }}$ Century, and recent efforts to revert back to gender-neutral pronouns. See Victor Mair, 'A Gender-Neutral Pronoun (Re)Emerges in China', Slate 12/26/2013. Thanks to Esther Klein, we have also learned of efforts to introduce gender-specific second-person pronouns in written Chinese in Taiwan.

${ }^{4}$ For example, it may be that there are moral reasons to preserve highly gendered indigenous languages in their current form. Our thanks to Andrea Pitts for helpful discussions of this issue.
} 
on Purity in Language ${ }^{\prime}{ }^{5}$ though as we discuss later, we have some general and specific reservations about this strategy.

Hofstadter imagines a world with race-specific English terms (hereon 'Renglish') that corresponds to the actual world's gender-specific English terms. Writing in the voice of "William Satire" - a fictional person whose name, prose, and arguments resemble those of the columnist William Safire-Hofstadter considers the "negrists" who would eliminate certain race-specific terms and thereby "radically change our language in order to "liberate" us poor dupes from its supposed racist bias." These terms fall into four categories, which have gender-specific counterparts in English.

\begin{tabular}{|l|l|l|}
\hline & Renglish & English \\
\hline Pronouns & whe; ble & he; she \\
\hline Honorifics & Master; Niss & Mister; Miss \\
\hline Suffixes & -oon & -ess \\
\hline Generic terms & whiteslaughter & manslaughter \\
\hline
\end{tabular}

First, we have third-person pronouns. Satire describes "shrill objections" from a black activist "to the age-old differentiaton of whites from blacks by the thirdperson pronouns 'whe' and 'ble'." This activist, Satire writes, argues that a single third-person pronoun should be used for "both" races - an idea Satire finds absurd. ${ }^{6}$ The fictional practice Satire describes corresponds to gendered thirdperson pronouns. Just as whe and ble mark white and black in Satire's English, our actual use of he and she mark male and female. ${ }^{7}$ Moreover, just like Satire's activist, we have elsewhere defended the idea that a single third-person pronoun should be used for everyone, regardless of gender. ${ }^{8}$

\footnotetext{
${ }^{5}$ Hofstadter (1985: 159-172).

${ }^{6}$ Note that Hofstadter, no doubt intentionally, has Satire assume that race is a strict binary.

7 There is considerable debate over the semantics of gender terms 'woman' and 'man', which we take to be relevant for the semantics of gender-specific terms like 'he' or 'Ms.' (Though strictly speaking, gender-specific pronouns take the relevant gender information as a presupposition: see Heim and Kratzer (1998), ch. 5 and 9). In particular, there is disagreement concerning when (if at all) gender terms mark biological features, gendered social roles, or internal gender identities. We remain neutral on this debate, as we do not think any proposed semantics will escape the worries we here raise for gender-specific terms. For further reading on the semantics of gender terms, see Bettcher (2013), Saul (2012), and Diaz-Leon (2016).

8 See Dembroff \& Wodak (2018). Again, we remain neutral here as to whether gender is best understood in terms of identity, biology, social position, or something else.
} 
Second, we have honorifics. Here's how Satire discusses complaints against three race-specific (and gender-neutral) honorifics in Renglish, 'Master', 'Niss', and 'Nrs.':

Nrs. Delilah Buford has urged that we drop the useful distinction between 'Niss' and 'Nrs.' [...]. Bler argument is that there is no need for the public to know whether a black is employed or not. Need is, of course, not the point. Ble conveniently sidesteps the fact that there is a tradition in our society of calling unemployed blacks 'Niss' and employed blacks 'Nrs.' [...] Nrs. Buford refuses to recognize this simple truth. Instead, ble shiftily turns the argument into one about whites, asking why it is that whites are universally addressed as 'Master', without any differentiation between employed and unemployed ones. ${ }^{9}$

Here again, Renglish corresponds to English. English honorifics 'Mrs.' and 'Miss' indicate the marital status of women, while men are universally addressed as 'Mr.'. (We now have an honorific for women that does not disclose marital status, 'Ms.'. We'll discuss it later.) And in both cases these honorifics encode a binary: between men and women (Mister/Ms.) or between whites and blacks (Master/Ns.).

Third, we have suffixes. Satire describes the "time-honored colored suffixes 'oon' and 'roon', found in familiar words such as ambassadroon, stewardoon, and sculptroon". ${ }^{10}$ This corresponds to how suffixes like 'ess' and 'ress' are used in English, which aren't employed as profligately as before (it is now rarer to talk of Emily Dickinson as a poetess, rather than a poet), but are still commonly used in familiar words such as 'actress' and 'waitress'.

Finally, we have generic terms. Linguistically, this is a somewhat miscellaneous category. In Satire's language, it includes compound nouns (chairwhite, mailwhite, repairwhite, clergywhite, middlewhite, Frenchwhite, forewhite) and verbs (whiteslaughter, whitehandle) that use white generically for all persons. Some uses of the term white are similar: "All whites are created equal" in the Declaration of Independence, and in "One small step for a white, a giant step for whitekind" as said by the first person on the moon. These race-specific terms have obvious counterparts in the 'masculine generics' in English. ${ }^{11}$

\footnotetext{
9 Hofstadter (1985: 159).

10 Hofstadter (1985), p. 162.

${ }^{11}$ For discussion, see Menegatti and Rubini (2017).
} 
We think Hofstadter's analogy elicits the intuition that English should be no more gender-specific than it is currently race-specific with respect to these parts of speech. That is, just as we do not have these distinct race-specific pronouns ("whe"), generic terms ("chairwhite"), honorifics ("Nrs") and suffixes ("-oon") in English, we should not have their gender-specific equivalents.

Hofstadter's intent in writing the piece was to support just this view. Indeed, he came close to making this point explicitly when he wrote, in the voice of Satire:

One of the more hilarious suggestions made by the squawkers for this point of view is to abandon the natural distinction along racial lines, and to replace it with a highly unnatural one along sexual lines. One such suggestionemanating, no doubt, from the mind of a madwhite-would have us say "he" for male whites (and blacks) and "she" for female whites (and blacks). Can you imagine the outrage with which sensible folk of either sex would greet this "modest proposal"?

We think the intuition that Hofstadter's analogy elicits is exactly right. Our goal will be to diagnose what would be wrong about the use of race-specific terms in Renglish, and note that the same considerations carry over to gender-specific terms in English.

But as we noted above, we have some reservations about this argument by analogy. A general reservation about analogies between race and gender is that these social identities aren't completely separable, ${ }^{12}$ they intersect. A similar point holds for gender- and race-specific terms. For example, as Duvall (2008) notes, honorific-plus-name variations were used in the South in the $20^{\text {th }}$ Century to mark the gender and race of both the speaker and subject. A white man named John Smith would be called "Mr. Smith" by other white adults, but "Mr. John" by children and African Americans. A white woman named Jane Smith would be called "Mrs. Smith" by white adults, and "Miss Jane" by children and African Americans. And African American adult called John would be called "John" or "boy", not "Mr. Smith", by white adults. It was not until Hamilton v. Alabama in (1964) that the US Supreme Court held that African Americans had the right to be addressed in court by the same gender-specific honorifics as whites. ${ }^{13}$

Another reservation is that, while Hofstadter's hypothetical is framed as a distant possibility, there are relevantly similar instances of race-specific language

12 See King 1988; Spelman 1988; Carastathis 2008; Mouffe and Laclau 1985.

13 There are also more subtle ways in which ways narrative constructions, rather than gender/race-specific terms, indicate gender and race. See, e.g., Bucholtz (2011). 
in English, including uses of the race-specific suffix '-oon'. ${ }^{14}$ (There are also, of course, plenty of examples of less relevantly similar but still significant racespecific terms, such as racial slurs and racially coded words, in English.) Given these reservations, and the differing genealogies and social meanings of actual race and gender categories, some might resist Hofstadter's analogy. In particular, some might think that Hofstadter relies upon intuitions problematizing racespecific terms that are not translatable or comparable to the intuitions problematizing gender-specific terms. ${ }^{15}$

On this issue, we think the devil is in the details: we think the best way to tell whether the analogy works is to explore whether the considerations against racespecific terms actually do apply to gender-specific terms. We take up that task in the next section. But if our discussion there isn't sufficient to assuage this concern, we think similar arguments by analogy could be made between genderspecific terms in English and hypothetical languages that marked other social identities, such as weight, class, or disability. ${ }^{16}$ While we acknowledge the significant differences between these social identities, we think similar moral concerns arise when languages embed these identities into their very grammar in the way that English currently embeds gender.

\section{What's Wrong with Gendered and Racialized Language?}

Intuitively, the actual English language should not become more racialized so as to mirror Renglish. But why, exactly? It is instructive to interrogate this intuition to see why Hofstadter's analogy between racialized and gendered language withstands scrutiny. We think there are three main factors that explain why it would be wrong to make English more racialized, and these same factors also explain why the actual gendered equivalents of this racialized language are also wrong.

\subsection{Stigma and Stereotypes}

The first reason concerns how language stigmatizes and stereotypes social groups. ${ }^{17}$

\footnotetext{
${ }^{14}$ Haslanger (2005: 11) has some examples: 'quadroon', 'octoroon'. However, '-oon' is rarely a race-specific suffix in English; it typically occurs in words borrowed from Romance languages (e.g. 'balloon').

${ }^{15}$ See Mayeri (2000: 1045) for related arguments against analogies between race and gender in legal contexts. We'd like to thank Andrea Pitts for helpful discussions here.

${ }^{16}$ See our example of weight-specific third-person pronouns in Dembroff and Wodak (2018: 398).

17 One relevant notion of 'stigma' loosely tracks Iris Marion Young's (2004) notion of being subject to "cultural imperialism". Groups subject to cultural imperialism, according to Young, when they
} 
Renglish stigmatizes blacks in part by making 'white' the generic term for all persons in phrases like 'chairwhite' and sentences like 'All whites are created equal': making 'white' the default treats non-whites as different, defective instances of persons. The same concern carries over to generic uses of 'man' for persons; indeed, feminist philosophers have long objected to generic uses of 'he' and 'man' in English. ${ }^{18}$ Similarly, having honorifics that communicate employment status for blacks but not for whites communicates that employment is central to the identity of blacks but not whites, and the same holds for honorifics that communicate marital status for women but not men.

Some might object, at this point, that race- and gender-specific terms need not have these stigmatizing effects. We can have such terms without making 'white' and 'man' the default; we can have race-/gender-specific honorifics that don't encode information about employment or marital status for blacks/women but not whites/men. So why not keep gender-specific language while also ensuring parity between male- and female-specific language-keeping the genders separate but equal, as it were?

We have three responses to this objection. First, note that it already requires some important changes to English and Renglish. It would require, for example, shifting to race- and gender-neutral alternatives to terms like whiteslaughter or manslaughter.

Second, even if white- or masculine-specific terms are not the default, there are reasons to think keeping races and genders separate is almost inevitably unequal. Consider the diminutive suffix -ess, and its counterpart in Renglish, oon. Even if the neutral (white/masculine) steward was not the default, stewardess and stewardoon are likely to remain objectionable. As feminists and linguists have noted for a long time, terms referring exclusively to women (e.g., spinster) that are the counterparts to neutral masculine terms (e.g., bachelor) acquire pejorative, trivializing, sexualizing, or in some other way subordinating meanings. ${ }^{19}$ Indeed, the linguist Chi Luu (2017) argues that gender-specific honorifics also mark respectability status: for example, while a male President is called "Mr.

are "defined from the outside" by stereotyped and inferiorized images, and so construed as "others". We think this notion applies to groups that are treated as abnormal/defective by standard generics.

18 Adele Mercier (1995), for example, argues that regardless of speaker intention, masculine generics are not gender-neutral, as they cannot be used to refer exclusively to women. Others, such as Horn and Kleinedler (2000) argue that masculine generics should not be used because they suggest that "normal" or typical humans are male. For further references, see Menegatti and Rubini (2017).

${ }_{19}$ See e.g. Lakoff (1973), Spender (1985), Baker (1992). 
President", a female President is not called the linguistic counterpart "Mrs. President," but rather is called "Madame President." Luu draws from this that "Mrs." is not simply the gendered counterpart of "Mr.", but also encodes a degraded respectability status. Mutatis mutandis, we expect, for racial terms in Renglish.

Third, even if gender-specific language were used equally without stigmatizing connotations, this will not avoid the stereotyping effects of genderspecific language..$^{20}$ A considerable amount of evidence supports the ("Whorfian") hypothesis that how we use language affects how we think in general, and how we use gendered language affects how we think about gender in particular. ${ }^{21}$ Many have argued that grammatical gender has pernicious effects on sexist practices and attitudes. ${ }^{22}$ There are also theoretical reasons to expect such results. Consider Renglish once more. If the most natural ways of referring to someone who writes would include information about their race (ble, authoroon), this would implicitly communicate that their race is important to their work. ${ }^{23}$ Of course, sometimes one's race is relevant. But it's not always relevant or, at least, not relevant to the extent that it calls for specific marking. And building racial classifications into pronouns and nouns this way makes it seem distinctly relevant to all and sundry features of social life. The parallel to genderspecific pronouns and suffixes should be clear. (For example, see Frye (1983: 22) on how English grammar requires one to reveal the author's gender to review 'his' or 'her' book.) Building social identities into the very grammar of the language communicates that the social identity in question is always relevant to explaining everything one does, and thereby helps to transmits essentialist views about social identities. ${ }^{24}$

${ }^{20}$ While there is debate over the best way to characterize stereotypes, for our purposes it is sufficient to recognize, following Beeghly (2015), that stereotypes "make generic claims about social groups".

${ }^{21}$ For a recent example, see Sato and Athanasopoulos (2018: 220-231): an object's grammatical gender categorization impacts cognition by influencing "conceptual gender" expectations about the object. For an even more recent example, see Tavits and Pérez (2019: 16781-16786): the use of gender-neutral pronouns "reduces the mental salience of males", which in turn is associated with more positive public attitudes toward females and LGBTQ persons.

22 See, e.g., Stahlberg et al., (2007); Wasserman and Weseley (2009): pp. 634-643.

${ }^{23}$ One way to understand the mechanism of this implicit communication is via Grice's maxim of "relation", which says that one should say things that are relevant to the discussion. For those who worry about this appeal to Gricean maxims, though, see Burnett (2017) and Khoo (2017) for alternative mechanisms that convey social meaning regardless of speaker intention.

${ }^{24}$ See e.g. Taylor (2013: 89): 'the failure of classical racialism means that "because they're black" is no longer an explanation for anything. It becomes, instead, a gesture at a request for an explanation'. Marilyn Frye (1983: 19-23) makes a similar point about gendered language. 


\subsection{Exclusion}

The second reason concerns who is excluded by Renglish. Renglish encodes the racial binary of white and black into the grammar of the language. What pronouns or suffixes or honorifics would Satire use for East Asians, or Native Americans, or Pacific Islanders? With only "whe" and "ble" as options, speakers must either treat Asians as if they are either white or black. Either way, they are misrepresented. ${ }^{25}$

Those who are neither white nor black are not the only people excluded by the binary. It would also face difficulties with people with both black and white ancestry. ${ }^{26}$ Would someone with one black great-grandparent be called "ble", in keeping with the one-drop rule? Or would they be called "whe", thereby erasing their black ancestry?

The basic problem is that Renglish treats racial categories as binary, exhaustive, and mutually exclusive, whereas many philosophers of race have long noted that there is a "continuous spectrum of varying morphological traits" (Mills 2000: 47). ${ }^{27}$ One might think the solution is to add racialized pronouns and suffixes and honorifics. But we think the solution is to have much less racialized language, not much more. To avoid misrepresenting anyone we' $d$ need an awfully large number of new distinct pronouns, suffixes, and honorifics. But proliferating race-specific language is doomed to fail. Pronouns, in particular, are "closed class" terms, or cognitively primitive terms that can function as shorthand for any person, thing, or concept. ${ }^{28}$ The problem is not that we cannot learn closed class terms. Children do, as do those learning foreign languages. The problem is that new closed class terms are far more difficult to learn, and hence resistant to change. Proliferating new race-specific prepositions is infeasible.

Why does infeasibility matter? For at least two reasons. ${ }^{29}$ First, infeasibility increases the risk of misrepresentation. Even the most conscientious individuals with all the resources to learn all of the appropriate pronouns and suffixes et al. would struggle to never deploy them inaccurately. We'd end up misrepresenting

\footnotetext{
${ }^{25}$ The focus on the white-black binary in American history has often been exclusionary to others. For example, the Mississippi Chinese were "[o]riginally classed with "blacks", but now viewed as essentially "white"," and still "burdened with an ambiguous racial identity" (Loewen 1988: 2).) ${ }^{26}$ In this respect, Renglish would entrench a general problem: that the "American biracial system does not permit the identification of individuals ... as mixed race", see Zack (1993: 4).

${ }^{27}$ Alcoff notes the ongoing "hegemony of the black/white binary in antiracist discourses" (2013).

28 See, e.g., Munte et al. (2001).

${ }^{29}$ It may also be that "ought implies feasible" (see Southwood 2016), but we're not relying on that here.
} 
others' racial identities too often. We should aim to adopt a disposition that minimizes the risk of even accidentally wronging others in this way. (Especially given that our mistakes are likely to be inequitably distributed.) Second, we shouldn't just be concerned with what the most conscientious individuals should do. We should strive to change grammatical norms that shape the behavior of even the relatively unconscientious, the exhausted, the distracted, and the overwhelmed. An infeasible policy is unlikely to become a new norm, since it's likely to be (known to be) habitually violated by so many of us so often. By contrast, a simple policy like 'Use "they" for everyone' is more likely to become a collective practice.

Notice that all of these considerations carry over to gendered terms in English, which encode a binary between men and women: "he" and "she", "Mister" and "Ms.", "actor" and "actress". This binary is not exhaustive or mutually exclusive. While "there are only two genders!" has become a rallying cry for some, we think it's false. Some people identify as having no gender. Some identify as being fluid between the binary genders. Some identify as third gendered. English speakers currently misgender such individuals on a regular basis in what is arguably a form of unlawful discrimination. ${ }^{30}$ Just as women are rendered invisible by generic uses of ' $h e^{\prime},{ }^{31}$ non-binary people are rendered invisible by generic uses of 'he or she' that presuppose that this disjunction covers all persons.

Perhaps you don't think gendered English terms do or should pick out persons' gender identities, and instead think they do and should be used as markers for reproductive traits. We won't argue with you (at least, not here). Even if you don't care about how people identify, and only care about their reproductive traits - e.g., chromosomes, gonads, genitalia - this position still will not justify retaining a binary set of gender-specific terms that function as euphemisms for reproductive traits. Given the non-trivial number of intersex conditions, there is little to no promise of finding any non-arbitrary standards that would divide biological traits neatly into two categories (male and female), much less categories that persons could be accurately sorted into based on appearance..$^{32}$ In short, regardless of whether we interpret gender-specific language in terms of gender identity or reproductive features, a binary encoded within gendered language excludes and marginalizes those who do not fit that binary. (The same point also holds for gendered social roles: consider Hijras,

\footnotetext{
30 See Jessica Clarke, (forthcoming): section III.B.3.

${ }^{31}$ See Saul and Diaz-Leon (2018), fn. 2, for discussion and references.

32 See Mantañez, A. (2017) "Beyond XX and XY: The Extraordinary Complexity of Sex Determination. Scientific American. https://www.scientificamerican.com/article/beyond-xx-andxy-the-extraordinary-complexity-of-sex-determination/
} 
Fa' afafine, and Khaniths). And this explains why the solution to generic uses of 'he' is not to use 'he or she', just as the solution to generic uses of 'whe' would not be to use 'whe or ble': treating the disjunction as if it exhaustively covers all persons excludes those who do not fit into the binary.

\subsection{Disclosure and Privacy}

The third reason concerns dilemmas that Renglish and English generate. Imagine that you live in a society that speaks Renglish. One day at work, you are making small talk with a colleague when they ask you whether you have any summer vacation plans. You say you have a vacation planned with your partner. Your colleague responds using the wrong race-specific pronouns for your partner: they didn't know that you're in a mixed-race relationship. Perhaps you'd prefer to keep this private--you think it's no one else's business, and you'd rather not have to engage with those who think that mixed-race relationships are morally wrong or disgusting. ${ }^{33}$ But you're in a bind. On the one hand, you could deceive your colleague by explicitly or tacitly affirming their inaccurate use of racespecific pronouns for your partner. On the other hand, you could refer to your partner accurately, and thereby disclose your partner's race and your mixed-race relationship. You might try a third option: avoiding race-specific language altogether. But given how pervasive race-specific terms are in Renglish, this requires awkward linguistic contortions-contortions that someone would only go through to try to hide the race of the person they were speaking about. Since the only reason to use such circumlocutions is to hide specific racial information, these contortions are likely to indirectly reveal that information anyway.

An analogous situation is regularly experienced by those in non-heterosexual relationships due to gender-specific terms such as third-person pronouns in English. People often are faced with the decision to either deceive their interlocutor or disclose the gender of a partner. ${ }^{34}$ The point generalizes to other contexts where it may be inappropriate to reveal gender information: with job

\footnotetext{
${ }^{33}$ In a March 2018 YouGov poll, 17\% of Americans said that they think interracial marriage is morally wrong (https://d25d2506sfb94s.cloudfront.net/cumulus uploads/document/y3tke5cxwy/econTabReport. pdf p. 92). Previous research suggests that many Americans who explicitly say that interracial marriage is morally acceptable still have disgust reactions to interracial couples (https://www.sciencedirect.com/science/article/pii/S0022103116300555). We can compare this to the $32 \%$ of Americans who morally oppose same-sex marriage (http://www.pewforum.org/factsheet/changing-attitudes-on-gay-marriage/).

${ }^{34}$ This situation is so common with respect to pronouns that it is popularly called 'playing the pronoun game' within LGBTQ communities.
} 
applicants, for instance. Given that one is expected to use terms like "he" or "she", "Mr." or "Ms." (or "Mrs.") etc., one can either deceive others by using a misleading term, or disclose the subject's gender directly by using an accurate term. Circumlocutions rarely avoid the problem. ${ }^{35}$

Renglish and English put people in a bind: speakers must either deceive or disclose with regard to racial or gender information that they have legitimate reasons to want to keep private. This is particularly galling since we should have more control over whether, when, and where we reveal such information. Grammatical norms should not violate our privacy and autonomy. Importantly, this is not to suggest that English ought to be altogether race- or gender-blind (see section 5), but rather that speakers should not be forced to reveal or lie about others' social identities when referring to them.

Again, this point holds regardless of whether one understands gender in terms of self-identification or anatomy. You have every right to privacy and autonomy about what's in your head and what's between your legs; everyone who uses third-person pronouns to describe you isn't entitled to know, or assume, information about either. Indeed, the point is arguably stronger if we think of gender in terms of reproductive features. It is at best inappropriate and arguably a form of sexual harassment to be forced to disclose or deceive others concerning one's own or another's genital status, much less to be forced to do constantly. ${ }^{36}$ But this is the fact of the matter in most contexts, where terms like 'she' are code for 'has-a-vagina' and terms like 'he' are code for 'has-a-penis'. Basic considerations of privacy weigh against using a language that forces us to perpetually communicate information about what's between people's legs while conversing.

\section{Objections}

We've argued that English should be no more gendered than it currently is racialized with respect to pronouns, honorifics, suffixes, and generics. We proposed three considerations that explain why such racialized terms - and, we suspect, similar terms that strongly mark any social identity - is morally wrong, and argued that they also apply to the analogous gendered terms.

\footnotetext{
${ }^{35}$ So long as gender-specific terms are predominantly used and expected, avoiding this language pragmatically implicates that the speaker has a reason to hide the subject's gender. The end result in most cases will be that the subject's gender is, in the end, indirectly (and perhaps involuntarily) disclosed.

${ }^{36}$ Bettcher argues that this function of language is a form of sexual violence (2007: 43-65).
} 
Some might remain unpersuaded. Why would that be? A few possibilities are worth considering. With each, it's worth asking whether it provides a compelling reason to resist the analogy: that is, to hold that Renglish should not be highly racialized as it is, but English can remain analogously highly gendered.

First, some might hold that Renglish is problematic because it is used to maintain an entrenched racial hierarchy, but English does not maintain a similar gender hierarchy between men and women because English-speaking countries are not very sexist.

We don't think that this is credible. From sexual harassment to the spate of violence from 'incels' - not to mention the reactions justifying, victimizing, or excusing this behavior - there's ample evidence of high levels of (often racially coded) misogyny in the English-speaking world (see especially Manne 2017 and hooks 1981). Indeed, we think the practice of using masculine terms as generic term for all persons wears its sexism on its sleeve, just as the practice of using 'white' as a generic term for all persons would wear its racism on its sleeve: an egalitarian society would not have this practice. ${ }^{37}$

Second, some might accept that sexism exists but deny that it provides a reason to eliminate gendered terms. Having a highly gendered English language is problematic only because it arises from and operates within sexist contexts. Since the real disease is the underlying sexism, the solution is to eliminate that, rather than its symptoms.

We think this response is mistaken on several fronts. For one, it's not true that highly gendered terms are problematic only because of sexism; just like highly racialized terms, they also exclude many and violate privacy and autonomy. For another, we argued that highly gendered language reinforces sexism. ${ }^{38}$ "Language", Wittig once argued, "casts sheaves of reality upon the social body, stamping it and violently shaping it;" and gendered languages like English and French "give way to a primitive ontological concept that enforces in language a division of beings into sexes" (1985: 4, 3). Among other things, gendered terms in English reinforce what Julia Serano calls 'oppositional sexism': the idea that male and female are "rigid, mutually exclusive categories." 39 Eliminating sexism may require eliminating some highly gendered terms; the latter are not a mere

\footnotetext{
${ }^{37}$ As Lakoff (1973: 78) argues, these gendered language discrepancies "exist in English for the same reason: each reflects...the difference between the role of women in our society and that of men." We note this applies to trans/nonbinary persons as well.

${ }^{38}$ A similar point is made about the role of discourse in racializing individuals (often in racist ways) in Lo (2016). Notably, Lo is concerned with broader features of discourse than merely racespecific terms.

${ }^{39}$ Serano (2007).
} 
symptom of the former. This becomes all the more obvious when we consider the role that gendered language plays in institutional decision-making. ${ }^{40}$

Third, one could hold that while there are strong reasons to eliminate racialized and gendered terms in Renglish and English, they are outweighed by reasons to keep those terms in English. What might those reasons be?

One possibility is that eliminating he and she would only reinforce the patriarchy: there is some evidence that gender-neutral references are by default categorized as male. ${ }^{41}$ But the same point applies to race-neutral references being by default categorized as white. If this is a good reason for English to remain as gendered as it is, it's a good reason for it to become racialized like Renglish.

Another possibility is that gender information is relevant for social coordination. One simple point is that gendered language helps us disambiguate. If we're discussing Romeo and Juliet, using 'he' or 'she' would allow you to clearly refer to one character and not the other. A more complex observation is made by Cailin O'Connor using models of cultural evolution: groups using social categories such as gender to coordinate behavior (particularly labor-related behavior) are - at least initially - "more efficient and more successful" than groups that do not use these categories. ${ }^{42}$ So gender information can be useful.

We don't think this line is promising. For one, racial information can be equally useful, but this does not seem to provide a sufficient justification for Renglish to be racialized. When discussing Trump and Obama, William Satire could use 'whe' or 'ble' to clearly refer to one President and not the other. And O'Connor's point isn't specific to gender; it works for using social categories like gender in general. For another, it's doubtful that this kind of usefulness outweighs the moral reasons against using such social categories to coordinate behavior. As O'Connor demonstrates, such divisions, even if intitially useful, facilitate the emergence of inegalitarian social systems that have "outcomes that look like discrimination, inequity, and distributional injustice" with "no beneficial function." We think that language plays a key role in facilitating such inequalities. As Lakoff succinctly put it, "Language uses us as much as we use language." ${ }^{43}$ In particular, gendered language reinforces separate, unequal roles for women and men, ${ }^{44}$ just as Renglish would plausibly reinforce separate, unequal roles for racial groups.

\footnotetext{
40 For discussion, see Robin Dembroff, 'The Non-Binary Gender Trap', The New York Review of Books January 30, 2018.

${ }^{41}$ See, e.g., Engelberg: "androcentricity in a genderless language may even increase the lexical, semantic and conceptual invisibility of women" (2002: pp. 109-132, 128).

${ }^{42} \mathrm{O}^{\prime}$ Connor (forthcoming).

${ }^{43}$ Lakoff (1973), 45.

${ }^{44}$ See Lakoff (1973), pp. 75, 76.
} 
Of course, there might be other benefits of retaining gender-specific pronouns et al.; for example, they allow for subversive uses that undermine sexist oppression. For example, when someone refers to god as "she", discomfort felt by those expecting "he" can send a powerful challenge regarding their preconceptions about god and gender.

It's not clear that retaining gender-specific pronouns et al. is necessary for engaging in such sexist subversive speech. We can use other gender-specific terms for these ends (see further, Section V): e.g., rather than refer to god as "she", one could refer to god as a "woman" or "mother". (After all, we engage in subversive speech about many other social categories without the aid of category-specific pronouns and suffixes.)

Moreover, we do not think that the benefits of retaining gendered pronouns et al. for subversive speech outweigh the costs of maintaining them. Consider an example of Hofstadter's in Renglish: "I have seen [g]od, and guess what? Ble's female!" By using "ble" against a background assumption of god's whiteness, the speaker uses a race-specific pronoun subversively. Weight-, age-, sexuality- or other identity-specific pronouns could be used in similarly subversive ways. We would not take such benefits to outweigh the costs of generally referring to persons using such pronouns.

A final possibility is that gendered language is necessary for the visibility of trans men and women: gender-specific pronouns, suffixes and honorifics give trans men and women linguistics tools to communicate to others how they would like to be addressed, what gender-norms they consider relevant to them, and so on. Moreover, partly for these reasons, men and women often prefer to be referred to by gender-specific pronouns, and those preferences should be respected..$^{45}$

This objection is more compelling, but we don't think it succeeds. Genderspecific terms like pronouns, honorifics, and suffixes are not the only way to articulate one's gender identity: trans men and women (and, indeed, everyone) can use regular nouns (' $\mathrm{man}^{\prime} /$ 'woman', 'brother'/'sister') as linguistic devices to communicate their gender identities in situations when they want to communicate those identities. ${ }^{46}$ This points to a benefit of our proposal. It gives everyone more

\footnotetext{
${ }^{45}$ One might also worry that female-specific terms play an important role in anti-sexist/feminist political movements (e.g., 'Run like a girl', 'Herstory', etc.). While flagging concerns about construing feminism as a female-specific movement, we are sympathetic with this point, and address it in Section 5 .

${ }^{46}$ Some might think we can just use pronouns the same way: by default, use 'they' for everyone; but when you learn someone is (e.g.) a woman, switch to using 'she'. We think this might be a practice we should follow en route to establishing a norm of using 'they' for everyone, but it's a worse long-term goal. Briefly, it's an unstable middle ground between the status quo and our
} 
control over when and how they make their gender identities visible, as we saw in the argument about disclosure and privacy.

Moreover, we doubt that there's an asymmetry with racialized terms here. For instance, someone who is Afro-Caribbean might be consistently 'read' as black by whites, and wish to make their Hispanic identity more visible; having specific Hispanic pronouns, suffixes, and honorifics would be a potent linguistic tool here too. This may be a reason to have racialized pronouns et al., but we doubt that it outweighs the reasons against racializing English. Why think the case with gendered terms is different?

Of course, one may grant that gendered and racialized terms stand or fall together, but still resist our view. Perhaps the intuition that Hofstadter's analogy elicits is misleading. It may, for instance, be a result of framing a hypothetical language in a way that spotlights the pernicious features of race-specific terms, but is silent about their significance with regard to visibility of and solidarity between minority racial groups. ${ }^{47}$

Even if this response undermines Hofstader's intuitions with respect to racespecific terms, we don't think it undermines our position with respect to genderspecific terms. To show why, we'll try a different way of addressing these objections to our key claim - that English should be far less gendered than it currently is - without relying on an analogy to Renglish. Recall the spectrum that languages form. If English should retain the gender-specific pronouns, honorifics, and suffixes it has in order to make people's gender identities more visible, why not make English more gendered? If we need third-person pronouns to make gender more visible, why not say the same for first- and second-person pronouns too? Why not make English like Hebrew, such that one must say, e.g., "I female-want a female-cookie"? In other words: if English should be more gendered than it is currently racialized, why shouldn't English be more gendered than it is currently gendered? We think, for instance, that we should adopt a gender-neutral singular third-person (like 'they' or 'ze') for everyone, in part because it would not misrepresent anyone's gender. ${ }^{48}$ If one finds it objectionable that on this proposal third-person pronouns fail to represent people's genders,

proposal. For one, it retains the problem of either having only distinct pronouns et al. for women and men (which is inegalitarian) or having distinct pronouns et al. for every gender (which is infeasible). For another, many people's linguistic dispositions with closed class words like pronouns are likely too inflexible: either they'll often automatically use 'she' for those that they simply assume are women (as in the status quo), or they'll continue automatically using 'they' for someone even after learning that this person is a woman.

${ }^{47}$ Thanks to Andrea Pitts for pushing this response in personal communication.

48 There are exceptions here: 'they' can pragmatically implicate that the referent has a nonbinary gender identity. In such contexts, though, 'they' is not functioning as a gender-neutral pronoun. 
why not also object that our current first- and second-person pronouns (' $\mathrm{I}$ ' and 'you') also fail to represent anyone's genders?

\section{Where Are We to Stop?}

At one point, again in the voice of Satire, Hofstadter writes of an opponent of race-specific terms:

Niss Moses would have us totally revamp [...] language to suit bler purposes. If, for instance, we are to substitute "person" for "white," where are we to stop? If we were to follow Niss Moses' ideas to their logical conclusion, we would have to conclude that ble would like to see small blackeys and whiteys playing the game of "Hangperson" and reading the story of "Snow Person and the Seven Dwarfs." And would ble have us rewrite history to say, "Don't shoot until you see the persons of their eyes"? Will pundits and politicians henceforth issue person papers? Will we now have egg yolks and egg persons? ${ }^{49}$

Some of what Satire says here is sheer sophistry. 'Egg whites' does not include 'white' as a racial term, any more than 'manatee' includes 'man' as a gender term. ${ }^{50}$ But 'where are we to stop?' is a serious question, because there are racespecific terms (in English, and in Hofstadter's story) other than the four categories we discussed above. And the same is true of gender-specific terms in English. For instance, there are generic nouns for gender groups (women, men), adjectives (masculine, feminine), and proper names (Anna, Ben). There are also terms that are ostensibly gender-neutral, but that, given their history and use, can be regarded as implicitly gender-specific (like pretty or handsome) ${ }^{51}$ Given what we have said about pronouns, honorifics, suffixes, and uses of genderspecific terms as generics for all persons, should we also strive to rid English of all of these instances of gender-specific terms? Likewise, we can ask: if the racespecific terms in Hofstadter's hypothetical are objectionable, should we strive to rid the actual English language of all race-specific terms?

\footnotetext{
${ }^{49}$ This explains the joke in the title: 'A Person Paper'.

50 Though etymologically, 'manatee' comes from a Native American term meaning 'breast, udder'.

${ }^{51}$ Beyond specific terms, there are numerous ways in which the structure of various discourses convey information about gender (as well as race, class, and other identities). It is an interesting question - and one we will not settle here-whether to interpret these discourses as 'genderspecific' or as indirectly conveying gender information.
} 
Some might think that our argument thus far commits us to opposing all gender-specific terms, and because this conclusion is objectionable (or even absurd), our argument must have gone wrong somewhere. In contrast, others might think that our argument commits us to opposing all gender-specific terms, and this is all well and good: all gender-specific terms should be rejected. We think both of these responses are too quick. Both fail to account for considerations of what linguistic features are changeable, and what features are needed for anti-sexism work. ${ }^{52}$ To illustrate, note that nothing about our view obviously condemns the term misogyny, even though it is transparently genderspecific. We should keep this word because none of the arguments we appealed to in condemning gender-specific honorifics and pronouns apply to misogyny, and because we need the term misogyny in order to recognize and rectify injustices committed against women. It's not objectionable, and it earns its keep.

It is a substantive question, then, whether other gender-specific terms such as feminine are more like misogyny (which must be kept) or more like Misses or she (which should and we think can be scrapped). Moreover, here we think that analogies between gender-specific and other identity-specific terms, like racespecific terms, are sure to break down. In order to resolve this question, we must look to the ways that gender-specific terms in particular socially function, and decide from there which terms are important for anti-sexist work. ${ }^{53}$ One way to go about this is to consider whether the arguments against Misses and she also show feminine to be objectionable, and if so, whether further considerations suggest that feminine earns its keep regardless. These considerations must be weighed with empirical input from linguists as to what mechanisms and targets for language change are realistic and effective.

Our stance on this is that the arguments against terms like Misses do apply to certain uses of terms like men and women, or masculine and feminine. Those uses are objectionable and should be avoided, if possible. For instance, when 'men and women' or 'ladies and gentlemen' are used to address all persons, speakers thereby reinforce the traditional gender binary and render invisible non-binary persons. When speakers use masculine and feminine as if all persons will fall under one descriptor, they reinforce the rigid gender norms associated with this traditional gender binary. This is objectionable. So are uses of gendered terms, and gendered patterns of language use, that reinforce gender stereotypes, such as

\footnotetext{
${ }^{52}$ On the first point, see Lakoff (1973): “The linguist can suggest which linguistic disparities...are changeable....and can thus help the workers in the real world to channel their energies most constructively." (76)

${ }^{53}$ The linguistic needs of anti-sexist work, including gender-based solidarity and visibility will not, we think, be interchangeable with the linguistic needs of, e.g., anti-racist, anti-abilist, or antifatphobic work.
} 
that of men as 'agentic' and women as 'communal', ${ }^{54}$ and of men as the norm. ${ }^{55}$ But not all uses of man and woman or masculine and feminine are like this. For instance, uses of these nouns in relation to the gender pay gap are important in precisely the way that misogyny is important. And uses of these adjectives within technical terms like toxic masculinity (stereotypically abusive masculine gender norms) or facial feminization (a medical procedure that is part of trans medical care) are similar.

Given this, we think that such gender-specific terms should be used less, and used with caution. But they should not be eliminated: so long as gender-based discrimination and prejudice exist, our ability to articulate it in its many manifestations - and to create gender-based solidarity with others-means that some gender-specific terms are necessary. But it's crucial here that we can relatively easily use these terms less, and with caution, in a way that isn't true of gender-specific terms that get encoded into grammar (he and she; 'I female-want a female-cookie'). Once that happens, we lack the ability to use gender-specific terms only where appropriate and relevant, and avoid them without implying gendered information. That's why we think English should eliminate some gender-specific terms, even if other gender-specific language that can be similarly problematic simply should be used with caution.

Our response so far has focused on exclusion and stigma, but a similar point applies to privacy and autonomy. In a sense, gender-specific proper names might seem to rid someone of their privacy and autonomy. For instance, say you are communicating online, and have to disclose your proper name. If your name is 'Rachel', this means implicitly disclosing that you are a woman. And since you may have good reason not to disclose your gender identity (without deception), this can be problematic. But notice that you can legally change your proper name, and you can also adopt a gender-neutral nickname (like 'Ray') without even filing paperwork. Unlike with pronouns, honorifics, adjectives, and so on, generally others do not simply assume one's proper name based on one's appearance, posture, or voice. We are authorities over our proper names: as a result, we have much more control over what this name will be. So perhaps there is some reason for parents to use gender-neutral names for their children, but it's not decisive. Moreover, telling parents to pick a gender-neutral name can sometimes veer close to the objectionable demand that they Anglicize their child's name. Consider Iceland, where most individuals can only have a patronym

\footnotetext{
${ }^{54}$ For a recent overview of the literature on gendered language and stereotypes, see Menegatti and Rubini (2017). See also Macaulay and Brice (1997).

55 See Silveira (1980) and Hamilton (1991) on the widespread practice of using gender-neutral terms for men (e.g., doctor) and gender-specific terms for similarly situated women (e.g., 'woman', 'lady doctor').
} 
whereby the suffix '-son' or '-dóttir' (depending on the declared sex of the child) is added to the genitive form of the father's name. It's one thing for Icelanders to argue for Iceland to allow individuals to adopt gender-neutral hereditary surnames. But it's another thing entirely for English speakers to demand that Icelandic immigrants do the same.

\section{Conclusion}

We live in a world saturated in both racial and gendered divisions. Our focus has been on just one place where attitudes about these divisions diverge: language. We suspect most everyone would be horrified at the idea of adding race-specific pronouns, honorifics, generic terms, and so on to English. And yet genderspecific terms of the same sort are widely accepted and endorsed. We think this asymmetry cannot withstand scrutiny. We've provided three considerations against incorporating additional race-specific terms into English, and argued that these considerations also support eliminating the analogous gender-specific terms. With respect to these parts of speech, in short: English should be no more gender-specific than it already is race-specific.

Should it not be gender-specific at all? We've suggested that, while we have good reason to massively pair down the number of gender-specific terms in English, we have further good reasons to preserve some gender-specific terms. Specifically, we suggested that some gendered terms are necessary in order to research, describe, and address gendered inequalities and experiences.

Our present goal was to draw attention to and challenge the justification for maintaining a variety of gender-specific terms in the English language - terms that, to borrow Wittig's words, "are instrumental in activating the notion of gender, [but] pass unnoticed" (1985: 5). We've focused on what we collectively ought to do: eliminate such terms, and make English less gendered. This leaves plenty of interesting and important questions about how we collectively and individually ought to act to realize this long-term goal. On this front, all we will say here is that we doubt there is much one-size-fits-all guidance that philosophers can provide. The history of advocacy for linguistic changes provides plenty of fruitful models. Sometimes change comes mostly from bottom-up activism, as with the adoption of an English honorific that does not disclose women's marital status, 'Ms.', in the 1960s and 70s. Sometimes change comes mostly from top-down institutional reform, as with the Swedish Academy's adoption of the gender-neutral pronoun 'hen' in 2014. So we leave the complex question of how to achieve this goal to future research, activists, institutions, and grassroots organizations. 


\section{References}

Alcoff, L. (2013) “The Black/White Binary and Antiblack Racism: The Black/White Binary and Antiblack Racism" Critical Philosophy of Race 1(1) 121124.

Baker, C. (1992). Attitudes and language (Vol. 83). Multilingual Matters.

Beeghly, E. (2015) “What is a Stereotype? What is Stereotyping?” Hypatia 30(4) 675-691,

Bettcher, T. (2013) “Trans Women and the Meaning of 'Woman'” In A. Soble, N. Power \& R. Halwani (eds.), Philosophy of Sex: Contemporary Readings, Sixth Edition. Rowan \& Littlefield. pp. 233-250;

Bettcher, T. (2007) “Evil Deceivers and Make-Believers: On Transphobic Violence and the Politics of Illusion." Hypatia 22(3): 43-65.

Bucholtz, M. (2011) “'It's different for guys': Gendered narratives of racial conflict among white California youth." Discourse \& Society 22(4): 385-402.

Carastathis, A. (2008). The invisibility of privilege: A critique of intersectional models of identity. In Les ateliers de l'éthique/The Ethics Forum (Vol. 3, No. 2, pp. 23-38). Centre de recherche en éthique de l'Université de Montréal.

Clarke, J. A. (2018). They, them, and theirs. Harv. L. Rev., 132, 894: section III.B.3.

Dembroff, R., \& Wodak, D. (2018). "He/She/They/Ze" Ergo, an Open Access Journal of Philosophy, 5.

Diaz-Leon, E. (2016) “Woman as a Politically Significant Term: A Solution to the Puzzle" Hypatia 31(2).

Engelberg, M. (2002) 'The communication of gender in Finnish'. In M. Hellinger \& H. Bußmann (eds.), Gender across languages vol. 2.

Frye, M. (1983). The politics of reality: Essays in feminist theory. Crossing Press. 
Guiora, A.Z. (1983) ‘Language and Concept Formation: A Cross-Lingual Analysis'. Behavior Science Research 18(3) 424-431.

Hamilton, M. C. (1991). 'Masculine bias in the attribution of personhood: People= male, male= people'. Psychology of Women Quarterly, 15(3), 393-402.

Haslanger, S. (2005). "What Are We Talking About? The Semantics and Politics of Social Kinds" Hypatia, 20(4), 10-26. https://doi.org/10.1111/j.15272001.2005.tb00533.x

Heim, I. and Kratzer, A. (1998) Semantics in generative grammar. Oxford: Blackwell.

Hofstadter, D. (1985) Metamagical Themas: Questing for the Essence of Mind and Pattern. Chapter "A Person Paper on Purity in Language." New York: Basic Books. pp. 159-172.

Horn, L. and Kleinedler, S. (2000) “Parasitic Reference vs. R-Based Narrowing: Lexical Pragmatics Meets He-Man", paper presented to the Linguistic Society of America, Chicago, 6 January. Online at: http://ling.yale.edu/sites/default/files/files/horn/HornKleinedler2000 heman.pdf

King, D. (1988) "Multiple Jeopardy, Multiple Consciousness: The Context of a Black Feminist Ideology" Signs: Journal of Women in Culture and Society 14(1) $42-72$.

Lakoff, R. (1973). Language and Woman's Place. Language in Society, 2(1), 45-80. Lo, A. (2016) "Suddenly Faced with a Chinese Village" in Raciolinguistics: How Language Shapes Our Ideas About Race, eds. Alim, H., Rickford, J., and Ball, A. OUP.

Loewen, J. (1988) The Mississippi Chinese: Between Black and White Harvard University Press. 
Macaulay, M. and Brice, C. (1997) `Don’t Touch My Projectile: Gender Bias and Stereotyping in Syntactic Examples', Language 73(4), 798-825.

Mayeri, S. (2000). “A Common Fate of Discrimination: Race-Gender Analogies in Legal and Historical Perspective." Yale LJ, 110, 1045

Menegatti, M. and Rubini, M. (2017) 'Gender Bias and Sexism in Language', Oxford Research Encyclopedia of Communication.

Mercier, A. (1995). A Perverse Case of the Contingent A Priori: On the Logic of Emasculating Language (A Reply to Dawkins and Dummett). Philosophical Topics, 23(2), 221-259.

Laclau, E. and Mouffe, C. (1985) Hegemony and Socialist Strategy: Towards a Radical Democratic Politics. Verso.

Münte, T, Wieringa, B., Weyerts, H., Szentkuti, A., Matzke, M. and Johannes, S. (2001) 'Differences in brain potentials to open and closed class words: class and frequency effects' Neuropsychologia 39(1).

O'Connor, C. (2019). The Origins of Unfairness: Social Categories and Cultural Evolution. Oxford University Press.

Sato, S. and Athanasopoulos, P. (2018) ‘Grammatical gender affects gender perception: Evidence for the structural-feedback hypothesis' Cognition 176: 220-231.

Saul, J. and Diaz-Leon, E. (2018) “Feminist Philosophy of Language" In Edward N. Zalta (ed.), The Stanford Encyclopedia of Philosophy.

Saul, J. (2012) “Politically significant terms and philosophy of language: Methodological issues." In Out from the shadows: Analytical feminist contributions to traditional philosophy, ed. Sharon Crasnow and Anita Superson. Oxford: Oxford University Press; and Serano, J. Whipping Girl (2007) Seal Press. 
Silveira, J. (1980). Generic masculine words and thinking. Women's Studies International Quarterly, 3(2), 165-178.

Southwood, N. (2016). Does "Ought" Imply "Feasible"? Philosophy E Public Affairs, 44(1), 7-45.

Spelman, E. V. (1988). Inessential woman: Problems of exclusion in feminist thought. Beacon Press.

Spender, D. (1985). Man-Made Language. Routledge.

Stahlberg, D., Braun, F., Irmen, L. and Sczesny, S. 'Representation of the sexes in language'. In K. Fiedler (Ed.), Social communication (2007): pp. 163-187;

Tavits, M. and Pérez, E. (2019) ‘Language influences mass opinion toward gender and LGBT equality' PNAS August 20, 2019116 (34)

Taylor, P. C. (2013). Race: A philosophical introduction. Polity.

Wasserman, B. and Weseley, A. '¿Qué? Quoi? Do Languages with Grammatical Gender Promote Sexist Attitudes?' Sex Roles, 61, (2009): 634-643.

Young, I. (2004). “Five Faces of Oppression. In L. Heldke \& P. O’Connor (Eds.), Oppression, Privilege, E Resistance. McGraw Hill.

Zack, N. (1993) Race and Mixed Race. Temple University Press. 